\title{
Mabuya cumingi (Reptilia: Scincidae): An Addition to the Herpetofauna of Lanyu Island, Taiwan
}

\author{
Hidetoshi OTA ${ }^{1 *}$ AND WeN-SAN HUANG ${ }^{2}$ \\ ${ }^{1}$ Tropical Biosphere Research Center, University of the Ryukyus, Nishihara, Okinawa \\ 903-0213, JAPAN \\ ${ }^{2}$ Zoological Department, National Museum of Natural Science, 1, Kuan Chien Road, \\ Taichung, 404 Taiwan, REPUBLIC OF CHINA
}

\begin{abstract}
An adult male Mabuya, recently collected from Lanyu Island, Taiwan, was identified as Mabuya cumingi, a species hitherto known only from Luzon Island of the Philippines, on the basis of small body size $(56.6 \mathrm{~mm}$ in snout-vent length), embossed dorsal head scales, five scales beneath toe $I$, and the presence of a dark middorsal stripe. Occurrence of this species on Lanyu Island was also confirmed by additional sighting records. Mabuya cumingi is regarded as a fourth reptile species representing a dispersal to this island from the Philippines.
\end{abstract}

Key words: Mabuya cumingi; Mabuya multicarinata; Scincidae; Lanyu Island; Taiwan; Philippines

\section{INTRODUCTION}

Lanyu Island is an islet of $45.7 \mathrm{~km}^{2}$ in area and $548 \mathrm{~m}$ in height, and is located ca. $60 \mathrm{~km}$ southeast of the main island of Taiwan and ca. $390 \mathrm{~km}$ north of Luzon Island, the Philippines. Since the description of Gekko kikuchii by Oshima (1912), a total of 18 species of reptiles, including three possible human commensals (Hemidactylus frenatus, Hemiphyllodactylus typus typus, and Ramphotyphlops braminus) and 15 putative native species, have been recorded from this island (Ota, 1991a,b; Lue et al., 1999).

A number of previous biogeographers ar-

* Corresponding author. Tel: +81-98-8958937; Fax: +81-98-895-8966.

E-mail address: ota@sci.u-ryukyu.ac.jp (H. Ota) gued that the fauna of Lanyu Island is characterized by a higher propotion of Philippine elements when compared with that of the main island of Taiwan (e.g., Kuroda, 1925; Kano, 1933, 1936). Of the 15 putative native reptiles hitherto known from Lanyu Island, three (G. kikuchii, Lepidodactylus yami, and Mabuya multicarinata borealis) are classified as the Philippine elements, whereas most of the remaining species are considered to represent dispersals from the main island of Taiwan (Ota, 1991a,b).

Recently, one of us (WH) collected a specimen of a strange skink from Lanyu Island. This specimen, deposited in the herpetological collection of the National Museum of Natural Science, Taichung, as NMNS 3371 , had keeled scales on the dorsum of the body and completely separated pterygoids with a palatal notch extending 
forwards to the level of the center of the eye, and thus was identified as a member of the genus Mabuya (see Greer [1970, 1977]). In this paper, we describe external characters of this specimen in detail, and compare it with species of Mabuya known from Taiwan and the Philippines to determine its specific status.

\section{Material ANd Methods}

The specimen was collected by hand from sparse grass near the coast, $3 \mathrm{~km}$ north of Tung-Ching Village, Lanyu Island $\left(22^{\circ} 04^{\prime} \mathrm{N}, 121^{\circ} 33^{\prime} \mathrm{E}\right)$, on 17 July 1999 . After being photographed in life (Fig. 1), the lizard was fixed in 10\% formalin, perserved in $70 \%$ ethanol, and then subjected to detailed examination of morphological characters. Measurements were taken to the nearest $0.1 \mathrm{~mm}$ with dial calipers. Definitions of characters follow those of Brown and Alcala (1980).

\section{RESUlts}

\section{Description of the present specimen}

A male with well-developed testes and convoluted epididymides; snout-vent length (SVL) $56.6 \mathrm{~mm}$; tail length $99.4 \mathrm{~mm}$; head length $12.2 \mathrm{~mm}$; head width $8.1 \mathrm{~mm}$; snouteye length $4.7 \mathrm{~mm}$; eye length $3.5 \mathrm{~mm}$; ear length $1.1 \mathrm{~mm}$; snout-forelimb distance $20.8 \mathrm{~mm}$; axilla-groin distance $28.8 \mathrm{~mm}$; forelimb length $17.7 \mathrm{~mm}$; hindlimb length $25.8 \mathrm{~mm}$.

Snout largely tapered, but rounded at tip; scales on dorsal surface of head embossed; rostral approximately twice as broad as high, rounded dorsally, in contact with frontonasal; supranasals long, narrow, not in contact at midline; frontonasal nearly as broad as frontal, in contact with frontal; prefrontals separated at midline; frontal elongate, broadly in contact with second supraoculars; supraoculars four, first smallest, second largest; frontoparietals not fused; interparietal incomplete, fused to parietals posteriorly; nuchals in two pairs; postnasal absent; anterior loreal distinctly higher than long, much shorter than posterior loreal; supralabials seven, fifth largest, beneath eye; seven infralabials; ear small, without lobules; each scale on dorsal and lateral surfaces of body with six or seven keels, ventral scales smooth, or slight-

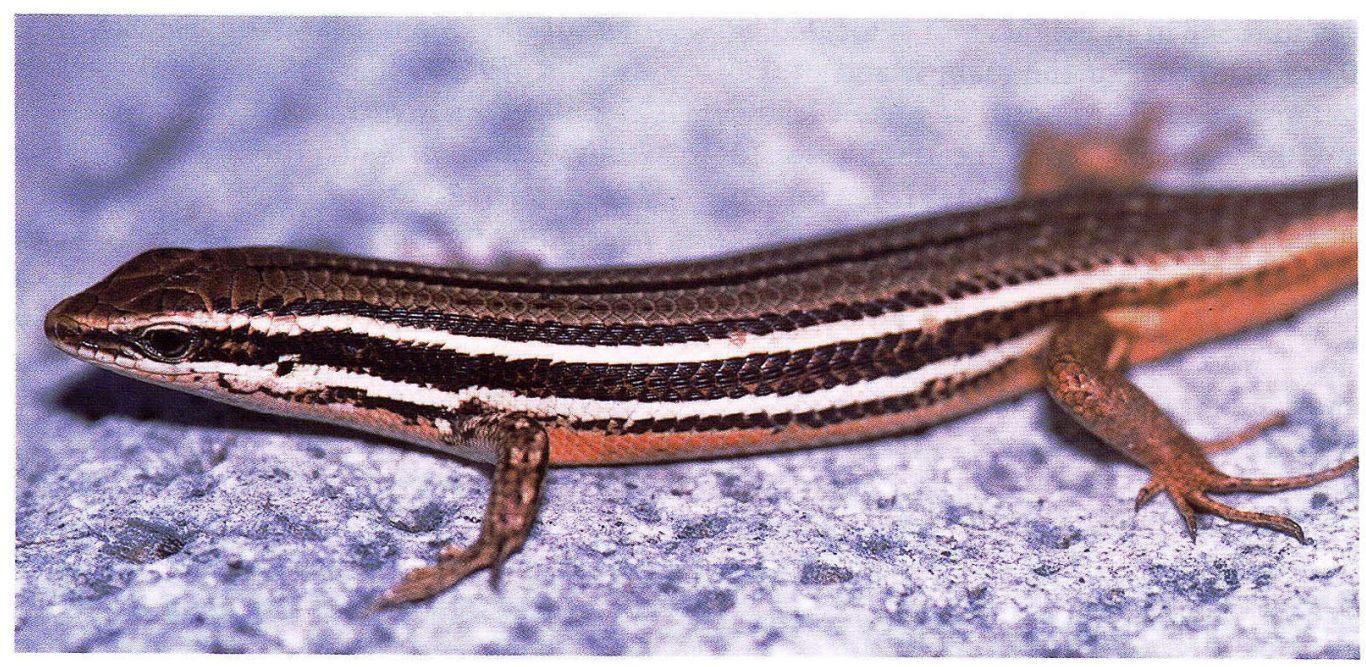

FIG. 1. Dorsolateral view of the specimen of Mabuya cumingi from Lanyu Island, Taiwan (NMNS 3371: $\mathrm{SVL}=56.6 \mathrm{~mm})$. 
ly rugose; 30 rows of scales around midbody; 43 vertebral scale rows between parietals and base of tail just above vent; preanals slightly enlarged; limbs well developed; finger III almost as long as finger IV; toe IV distinctly longer than toe III; subdigital scales 5-5, 9-9, 14-14, 15-15 and -8 on left-right fingers I, II, III, IV and V (left finger $V$ damaged), and 5-5, 10-10, 15-16, 21-21 and 13-13 on left-right toes I, II, III, IV and V, respectively; tail not damaged or regenerated.

In life, dorsal surfaces of head and body light grayish tan, with black middorsal stripe; additional longitudinal black stripes, separated from each other by white interspaces, in dorsolateral, lateral, and ventrolateral regions; lateral stripe, running from nasal and eye to above base of hindlimb broad, the others narrower (Fig. 1). In preservative, dorsal ground color and white interspaces faded to dark gray and light gray, respectively, making longitudinal dark stripes indistinct.

\section{Comparisons}

Three species of Mabuya, M. longicaudata, M. multifasciata, and M. multicarinata borealis, have been recorded from Taiwan (Ota et al., 1994; Lue et al., 1999). The present specimen differs from the three spe- cies in a much smaller body size, because adult SVLs of these species well exceed $60 \mathrm{~mm}$ (Okada et al., 1992; Ota et al., 1994). Furthermore, it differs from M. longicaudata and $M$. multifasciata in having distinctly embossed head scales, because in the latter species, scales covering the dorsal surface of head are smooth, or only slightly rugose (Ota et al., 1994). From M. multicarinata borealis, the present specimen also differs in having a greater number of vertebral scale rows (43, vs. 34-41), fewer scales beneath toe IV (21, vs. 24-28), and a distinct middorsal stripe (vs. no middorsal stripe: Ota, 1991a).

Most of those and other characteristics of NMNS 3371 are shared with $M$. cumingi and $M$. indeprensa from the Philippines (Brown and Alcala, 1980). So, we compare the present specimen with these two species in detail (Table 1). Brown and Alcala (1980) reported that both of these Philippine species have a distinct interparietal which almost always separates parietals completely. In the present specimen, however, the interparietal is incomplete because it is fused with parietals posteriorly. The Lanyu specimen differs from $M$. indeprensa in having shorter hindlimbs in relation to the axilla-groin distance, and fewer scales beneath toe I. States of these and

TABLE 1. Comparisons of characters among the Lanyu specimen of Mabuya, and M. cumingi and M. indeprensa from the Philippines. Abbreviations are: SVL, snout-vent length; HLL, hindlimb length, AGD, axilla-groin distance; IP, interparietal; MSR, midbody scale rows; VS, vertebral scale rows; TIS, subdigital scales beneath the toe I; TIVS, subdigital scales beneath the toe IV.

\begin{tabular}{lccc}
\hline Character & Lanyu specimen & M. cumingi $^{*}$ & M. $_{\text {indeprensa }}{ }^{*}$ \\
\hline SVL (mm) & 56.6 & $39.5-54.0$ & $45.6-66.6$ \\
HLL/AGD (\%) & 90.0 & $74-96$ & $94-116$ \\
HLL/SVL (\%) & 45.6 & $37-45$ & $45-58$ \\
IP & incomplete & distinct & distinct \\
MSR & 30 & $28-32$ & $30-34$ \\
VS & 43 & $40-47$ & $41-48$ \\
TIS & 5 & $5-6$ & $6-8$ \\
TIVS & 21 & $16-21$ & $18-24$ \\
\hline
\end{tabular}

* Data for these species in the Philippines were taken from Brown and Alcala (1980). 
most other characters in the present specimen are shared with $M$. cumingi, except for SVL, which is slightly greater in the Lanyu specimen than in the latter.

\section{DisCUSSION}

Morphological comparisons indicate that the Lanyu specimen most resembles $M$. cumingi, but differs from the species in having slightly greater SVL and an incomplete interparietal. Considering that the body size often varies extensively among conspecific insular populations in reptiles (see Ota et al [1995] and papers referred therein for examples), such a difference in SVL between the present specimen and $M$. cuming $i$ from the Philippines may have little taxonomic significance. Moreover, it is probable that the interparietal condition in the Lanyu specimen represents an anomaly rather than a stable population feature. We thus identify the specimen as $M$. cumingi. Further detailed analysis of variation on the basis of additional specimens is desired to verify those assumptions.

During the fieldwork on Lanyu Island in 1995 (by HO) and 1997-1999 (by WH), both of us observed several other individuals with body size and color pattern similar to those of the present specimen. Thus, although the present record was made only on the basis of a single voucher specimen, we are almost certain that there is an established breeding population of $M$. cumingi on Lanyu Island. All individuals sighted were found in relatively open environments near the coast, and appeared to be most active on clear mornings and at dusk.

In the synopsis of the lizards of Taiwan, Lin and Cheng (1990) provided three color photographs as those of $M$. multicarinata. The animals photographed, however, showed a color pattern almost identical with that of the present specimen including a distinct middorsal stripe on body. Therefore, although the locality of the individual photographed was not given in that book, it is most likely that it actually represented $M$. cumingi from Lanyu Island rather than $M$. multicarinata.

Since the original description by Brown and Alcala (1980), Mabuya cumingi has been known only from Luzon Island. Thus, the present finding seems to represent another example of reptilian dispersals to Lanyu Island from the Philippines (Ota, 1991a, b).

\section{ACKNOWLEDGMENTS}

HO thanks M. Toda and S. Iwanaga for helping with his fieldwork on Lanyu Island, and $\mathrm{WH}$ is grateful to $\mathrm{C}$. $\mathrm{H}$. Chang for his assistance. This research was partially supported by grants from Kuo Wu Hsiu Luan Foundation and National Museum of Natural Science (to WH), and from the Fujiwara Natural History Foundation (to HO).

\section{Literature Cited}

Brown, W. C. AND A.C. Alcala. 1980. Philippine Lizards of the Family Scincidae. Silliman University Press, Dumaguete, Philippines. $\mathrm{i}-\mathrm{xi}+264 \mathrm{p}$.

GREER, A. E. 1970. A subfamilial classification of scincid lizards. Bull. Mus. Comp. Zool. 139(3): 151-184.

GreER, A. E. 1977. The systematics and evolutionary relationships of the scincid lizard genus Lygosoma. J. Nat. Hist. 11(3): 515-540.

KANO, T. 1933. Biogeographical studies of Kotosho. 2. Geol. Rev. Japan 9(6): 475-491. (in Japanese)

Kano, T. 1936. Some problems concerning the biogeography of Kotosho, near Formosa. 7. Geol. Rev. Japan 12(12): 1107-1133. (in Japanese with English abstract)

KURODA, N. 1925. On the distribution of Japanese birds. Chigaku Zasshi 37: 369-380. (in Japanese)

LiN, J.-Y. AND H.-Y. Cheng. 1990. A Synopsis of the Lizards of Taiwan. Taiwan Museum, Taipei. i-xiii +176 p. (in Chinese)

Lue, K.-Y., M.-C. Tu, ANd G. Shang. 1999. A Pictorial Guide to the Amphibians and Reptiles of Taiwan. Union for the Nature Conser- 
vation, ROC \& Great Nature Press, Taipei, Taiwan. (in Chinese)

OKada, S., H. Ota, M. Hasegawa, T. Hikida, H. Miyaguni, AND J. Kato. 1992. Reproductive traits of seven species of lygosomine skinks (Squamata: Reptilia) from East Asia. Nat. Hist. Res. 2(1): 43-52.

Oshima, M. 1912. Description of a new gecko from Botel Tobago Island. Philippine J. Sci. 7(4): 241-242, pls.1-2.

ОтА, H. 1991a. Taxonomic status of Mabuya multicarinata (Gray, 1845)(Scincidae: Squamata: Reptilia) from Taiwan, with comments on the herpetofauna of Lanyu Island. Bull. Coll. Sci., Univ. Ryukyus (51): 11-18.

ОтА, H. 1991b. Systematics and biogeography of terrestrial reptiles of Taiwan. p. 47-112. In:
Y.-S. Lin and K.-S. Chang (eds.), Systematics and Biogeography of Terrestrial Reptiles of Taiwan. Council of Agriculture, Taipei, Taiwan.

Ota, H., H.-W. Chang, K.-C. Liu, and T. HikIDA. 1994. A new record of the viviparous skink, Mabuya multifasciata (Kuhl, 1820)(Squamata: Reptilia), from Taiwan. Zool. Stud. 33(1): 86-89.

Ota, H., M. Shiroma, and T. HiKida. 1995. Geographic variation in the endemic Ryukyu green snake Cyclophiops semicarinatus (Serpentes: Colubridae). J. Herpetol. 29(1): 44-50.

Accepted: 7 April 2000 